\title{
An assessment of validity and responsiveness of generic measures of health-related quality of life in hearing impairment
}

\author{
Yaling Yang • Louise Longworth · John Brazier
}

Accepted: 14 April 2013/Published online: 26 May 2013

(C) The Author(s) 2013. This article is published with open access at Springerlink.com

of EQ-5D was relatively poor and weak validity was suggested by limited evidence. The evidence on SF-6D was too limited to make any judgment. More head-to-head comparisons of these and other preference measures of health are required.

Keywords Validity - Responsiveness · EQ-5D · HUI3 . SF-6D · Hearing impairments

$\begin{array}{ll}\text { Abbreviations } \\ \text { ADPI } & \text { Audiological Disability Preference Index } \\ \text { AI } & \text { Amsterdam Inventory } \\ \text { BEPTA } & \text { Better ear unaided pure-tone average } \\ \text { CI } & \text { Cochlear implant } \\ \text { EQ-5D } & \text { Euroqol 5 dimensions } \\ \text { EQ-VAS } & \text { Euroqol Visual Analogue Scale } \\ \text { ES } & \text { Effect size } \\ \text { GPBMs } & \text { Generic preference-based measures of health } \\ \text { HHDI } & \text { Hearing Handicap and Disability Index } \\ \text { HHIE-S } & \text { Hearing Handicap Inventory for the Elderly } \\ \text { HRQoL } & \text { Health-related quality of life } \\ \text { HSUVs } & \text { Health state utility values } \\ \text { HUI3 } & \text { Health Utilities Index 3 } \\ \text { ICC } & \text { Intra-class correlation coefficients } \\ \text { LVAS } & \text { Large vestibular aqueduct syndrome } \\ \text { NCIQ } & \text { Nijmegen cochlear implant questionnaire } \\ \text { NICE } & \text { National institute for health and clinical } \\ & \text { excellence } \\ \text { QALY } & \text { Quality-adjusted life year } \\ \text { QWB } & \text { Quality of well-being } \\ \text { SF-6D } & \text { Short-form 6 dimensions } \\ \text { SF-36 } & \text { Short-form 36 } \\ \text { SF-12 } & \text { Short-form 12 } \\ \text { SG } & \text { Standard gamble } \\ \text { SRM } & \text { Standard response mean } \\ & \end{array}$


SSQ Speech spatial and qualities of hearing scale for parents

TTO Time trade-off

VAS Visual Analogue Scale

\section{Introduction}

Economic evaluations using a cost-utility framework have been increasingly used to support decision-making in the allocation of health resources and priority setting [1-3]. Cost-utility analyses assess health care interventions in terms of the incremental cost per quality-adjusted life year (QALY) gained. QALYs combine length of life with a quality of life where the quality of life component is usually based on health state utility values [4].

One common way to obtain health state utility values is to use one of the generic preference-based measures (GPBMs) of health-related quality of life. Examples of the most commonly used GPBMs include the EuroQol 5 dimension (EQ-5D) [5, 6], Short-form 6 dimension (SF-6D) [7] and the Health Utilities Index (HUI3) [8]. For the purpose of economic evaluation, these measures have the advantage of reflecting the value people place on different dimensions or levels of health and enable comparisons of health outcomes to be made across conditions. EQ-5D has 5 health dimensions (mobility, self-care, usual activities, pain/discomfort and depression/anxiety). Each dimension has 3 levels of severity in the original version, and a version with 5 levels of severity has recently been developed [5, 9]. Derived from the Short-form 36 and Short-form 12 health questionnaires, the SF-6D has 6 dimensions (physical functioning, role limitation, social functioning, bodily pain, mental health and vitality), and each dimension has 4-6 severity levels. The HUI3 has 8 dimensions (vision, hearing, speech, ambulation, dexterity, emotion, cognition and pain), and each dimension has 5 or 6 severity levels. These measures differ in terms of the description of health. The HUI3 can be seen as a 'within the skin' measure of health and includes sensory dimensions such as vision, speech and hearing. EQ-5D and SF-6D focus more on how health impacts on functioning in life, but nonetheless there are important differences in coverage, such as EQ-5D not having vitality and SF-6D containing role and social functioning dimensions compared to usual activities in EQ-5D. Apart from the different descriptive systems, the measures also differ in terms of the methods used to estimate health state values.

Empirical evidence has confirmed that health state utility values obtained from these three GPBMs are different from each other [10-14]. In order to allow comparability between conditions, in the United Kingdom, the National Institute for Health and Clinical Excellence has prefers the use of a single GPBM, the EQ-5D [15]. However, GPBMs have attracted criticism for failing to capture important aspects of health and insensitive to the change of health states because one or more important dimensions of health relevant to a medical condition have been excluded [16-18] [19-21]. National Institute for Health and Clinical Excellence recognized that there may be specific circumstances in which the EQ-5D is not appropriate and offers some advice for these circumstances; however, it does not identify those areas where EQ-5D is inappropriate nor provide criteria to determine this.

More evidence on the performance of EQ-5D and other GPBMs is required for a wider range of conditions and/or treatments to demonstrate whether these measures are appropriate for these conditions in order to judge when alternative measures should be considered. The assessment of the validity and responsiveness of GPBMs is fraught with conceptual and empirical problems owing to the lack of a gold standard measure. However, by taking into account of a range of evidence on specific conditions in a systematic and transparent way, it is possible to judge the performance of the instruments [22]. This is important in order to help inform which measures should be included for the assessment of benefits of specific health interventions, or for interpreting the evidence from population studies that include such instruments. For example, recently in the United States, the National Health Measurement Study (http://www.health measurement.org/NHMS.html) attempted to build a versatile 'toolbox' for this purpose, and EQ-5D, Short-form 36 version 2 (from which SF-6D can be derived) and HUI were included in the toolbox (http://www.healthmeasurement. org/NHMS.html).

Hearing impairment is one of the most common chronic health problems in Western society, in part due to the growth of the elderly population, affecting $15 \%$ of the adult population [23]. Hearing loss affects a person's ability to communicate, social participation, independence, employment and overall quality of life [23]. Previous research has suggested that health state utility values obtained from people with hearing impairments are different using different generic instruments [24]. A review of the evidence on the validity of GPBMs in hearing impairment has not been previously undertaken. The aim of this study was to systematically review the published literature to assess the reliability, validity and responsiveness of three key generic measures of health-related quality of life (EQ-5D, HUI3 and SF-6D) in people with hearing impairment.

\section{Methods}

Search strategy and data identification

The objective of the literature review was to identify published papers reporting evidence of the performance of 
EQ-5D, HUI3 and SF-6D in patients with hearing impairments.

A broad search was conducted to identify studies reporting EQ-5D, SF-6D and HUI3 to examine the healthrelated quality of life of patients with a hearing impairment. BIOSIS, CINAHL, EMBASE, MEDLINE, PsychINFO and Web of Science electronic databases were searched. The database available from the EuroQol Group Website was also searched but comparable databases for HUI3 and SF-6D are not available. The search focused on key words search, including 'hearing impairment/disorder', 'euroqol/EQ-5D', 'hui3' and 'sf6d', all with alternative spellings. The search strategy is presented in Appendix 1. The criteria for inclusion were that the study population had a hearing impairment, the study reported at least one from the EQ-5D, SF-6D or HUI3 and reported another measure of quality of life (generic- or condition-specific) or a measure of clinical severity, or direct valuation of health. Papers only reporting EQ-VAS (EuroQol Visual Analogue Scale) scores were excluded as the main interest was the descriptive systems and utility indices of the three measures. Papers that only used vignettes or own health state valuations, and not one of the three generic measures, were excluded. There was no restriction relating to the type of study. Due to resource limitations, only English language studies were reviewed.

\section{Analytic strategy}

\section{Data extraction}

Considering the aim of the study and reviewing forms used for similar studies in other disease areas [17, 25], a template was developed to extract data in a standardised format including the following:

- Study characteristics - country, type of hearing impairment, disease or treatment stage, any treatment given, study design;

- Participant characteristics-number of participants, age, gender, ethnicity, missing data;

- Instruments used-EQ-5D/SF-6D/HUI3, other generic measures of health-rated quality of life, conditionspecific health-related quality of life measures and clinical measures of disease severity, patient's own health state valuations (e.g. Visual Analogue Scale (VAS), Time trade-off (TTO) and Standard Gamble (SG));

- Health state utility values-mean of utility index, scoring algorithm;

- Construct and convergent validity-methods of assessment and results;

- Responsiveness-methods of assessment and results.
- Reliability—methods of assessment and results.

\section{Quality assessment of studies}

For the review, of the most importance was the relevance of the study in terms of the patient population and inclusion of evidence to answer our research question. Nevertheless, the quality of studies was assessed by examining study design, recruitment process, sample size and the extent of missing data reported. The intention of the assessment of quality was not to exclude relevant studies. Rather, it gives some indications of quality to assist with the interpretation of the findings. It should be noted that some studies may be of high quality for their research question, but provide limited information for the assessment of validity, reliability and responsiveness. For example, a case-control study may be well designed and conducted, but offer information limited to the presence or absence of hearing problems, and not detailed information on the severity of the condition.

\section{Assessment of validity}

Validity is defined as how well an instrument measures what it was intended to measure $[22,26]$. Ideally, validity would be assessed by comparing an instrument to an established gold standard. However, in the case of healthrelated quality of life, no gold standard measure exists. Therefore, construct validity was assessed by making comparisons with other measures of quality of life and disease severity, and assessing the totality of that evidence to see whether the results from the GPBMs reflect the patterns in scores seen in those other measures [22].

A common test to identify construct validity is the 'known group' method [22]. This is determined by the degree to which an instrument can demonstrate different scores for groups know to vary on the variables being measured. In this study, health state utility values are compared between groups of patients that are defined in terms of disease severity and trends in the pattern of utility, statistical tests (e.g. $t$ test) and regression were used for assessment. The patient population could be stratified on the basis of a clinical indicator or a health-related quality of life measure (generic- or condition-specific). A less stringent test of construct validity is to define groups using a case-control analysis where scores of patient group and non-patient groups or general population are compared.

Another type of construct validity is known as convergent validity [22]. This is defined as the extent to which one measure correlates with another measure of the same concept (although this measure is not regarded as gold standard). In this review, the extent to which EQ-5D, 
SF-6D or the HUI3 correlated with other measures of hearing problems or health-related quality of life was examined based on statistics including correlation coefficients or regression analysis with hearing-specific healthrelated quality of life measures or measures of hearing loss.

\section{Assessment of responsiveness}

Responsiveness is the ability to measure change. A pre/ post-intervention study which reports EQ-5D, SF-6D or the HUI3 and another valid measure of health change would allow the responsiveness of a measure due to change in health status to be identified. As with the tests of validity, it is important to consider whether the measures of health change that used for comparison are valid themselves. In addition, it is important to consider whether other health changes not directly related to the condition could have impacted upon health-related utility (for example, side effects of treatment).

\section{Assessment of reliability}

The reliability of a measure is defined as its ability to reproduce results when measurements are repeated on an unchanged population [22]. Reliability can be measured by retesting and reporting either the correlation or difference between estimates. For this study, the measures were considered reliable if they demonstrated no change in health-related quality of life when the other reference measures also demonstrated no change in health.

\section{Presentation of data}

Data were presented in a series of summary tables as well as brief text, providing information on characteristics and quality assessment of included studies, the measures included, methods and result for validity assessment, methods and results for responsiveness assessment. At the end, a table providing an overview of performance of EQ5D, HUI3 and SF-6D was presented recording the findings as a ' $\sqrt{ }$ ' if the evidence supported the statement, or ' $x$ ' if the evidence did not support the statement, or '?' if the evidences were mixed and conclusion could not be made, or 'N/R' if no information was reported. If the pattern and direction of EQ-5D were consistent with other measures in terms of difference between groups or change over time, this was considered as supporting evidence. Correlation coefficients were grouped as small $(<0.3)$, moderate (0.03-0.5) and strong $(>0.5)$, and a significant predictor of regression was recorded as ' $\sqrt{ }$ '.

\section{Results}

Search results

Bibliographic searching was completed in July 2010. The search strategy identified 119 articles. After reviewing titles and abstracts, 70 papers were excluded. Forty-nine papers were reviewed in full, and a further 31 were excluded and 18 papers were included in the final review (see Fig. 1). Papers were included if they provided sufficient evidence to assess the validity, responsiveness and reliability of EQ-5D, HUI3 and SF-6D. However, the paper did not have to have been designed for this purpose. Papers were excluded if they did not include one of the generic measures of interest. Papers were also excluded if validity or responsiveness could not be assessed because no other clinical or quality of life measures were included, and differences over time or between interventions were not reported. Since the focus of the review is preference-based measures, papers only reporting Visual Analogue Scale scores were also excluded.

Quality assessment and characteristics and of included studies

Most studies were not designed to specifically assess the validity, reliability and responsiveness of the instruments, but all provided data in sufficient detail to allow an assessment to be made. A range of recruitment procedures was noted in the studies included in the review. Some were cross-sectional observational studies [27, 28] but the majority were prospective or retrospective before-after studies [29-32]. Studies had well-defined inclusion/exclusion criteria in recruitment. Sample size ranged from 20 to 3,272 with most of studies had around 100 participants but two studies only had around 20 participants [29, 33]. For longitudinal studies, no study had extremely high levels of missing data. The reporting in these papers was reasonably clear. After quality assessment, no studies were excluded from the review.

The main characteristics of the 18 papers included in this review are shown in Table 1 . The four papers by Joore et al. [31, 32]; Joore [34, 35] reported the results of one specific study and similarly the two papers by Vuorialho et al. [36] reported a single study, resulting in 14 studies in total. The studies were undertaken in a range of countries, including United Kingdom, the Netherlands, USA, Canada and Finland. Some studies recruited patients with specific hearing problems, for example, Large Vestibular Aqueduct Syndrome [29], profoundly deaf or conductive or mixed hearing loss [37, 38]. Twelve papers reported hearing loss of their sample using clinical indicators such as the better 
Fig. 1 Flow diagram showing selection of studies

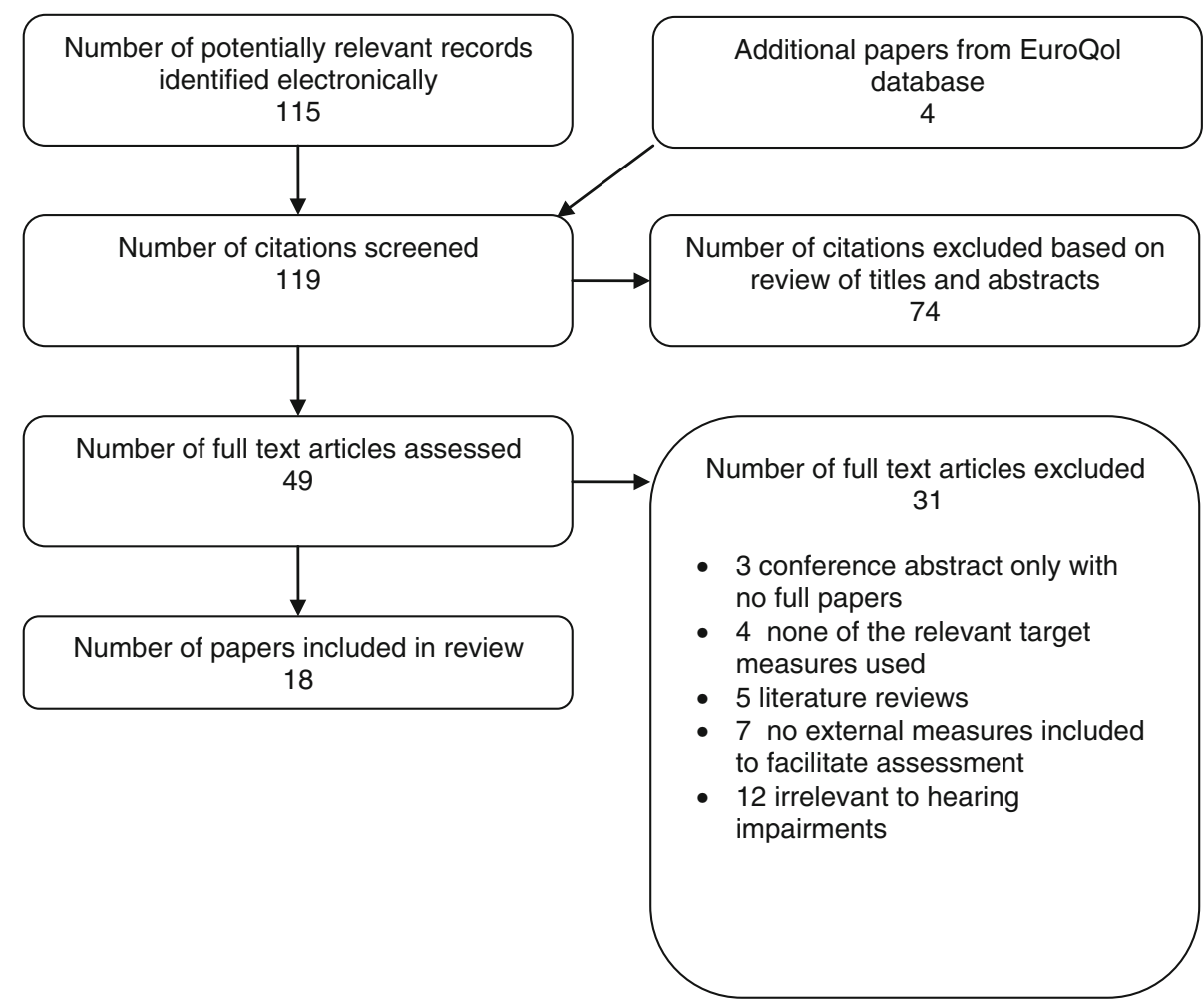

ear unaided pure-tone average. As shown in Table 1, the level of hearing loss varied between studies.

Five studies included young children with hearing impairments (mean ages of the samples ranged from 7.3 to 9.3 years old), and the remaining studies included adults in their studies with most focussing on older adults over 60 years. The studies involving children used parents or caregivers as proxies to assess health-related quality of life of children.

Measures and clinical indicators used in the studies included

Table 2 summarises the measures which have been used in the 18 papers. For the three generic preference-based measures of interest, 11 papers reported EQ-5D, 11 reported HUI3 and 1 used the SF-6D (alongside EQ-5D and HUI3). Among those studies that used EQ-5D, most reported the EQ-5D index based on the tariff of UK population values. In two cases, it was unclear which tariff of population values had been used. Three papers also reported responses on the five EQ-5D dimensions alongside the utility indices using tariff [31, 34, 39]. One study [30] also compared EQ-5D results using the UK and Dutch tariff. Only the Canadian tariff was used to value the HUI3. Two studies used Quality of Well-being (QWB, another generic preference-based measure of health) alongside EQ-5D or HUI3.
A total of 11 papers also reported Visual Analogue Scale (VAS) results including: EQ-VAS, a general health VAS, a hearing-specific VAS and a general quality of life VAS. In total, 7 papers reported the EQ-VAS and used imaginable best and worst imaginable health as anchors. Among them, 4 publications related to a single study reported the results of a hearing-specific VAS [31, 32, 34, 35] using 'deaf' and 'perfect sense of hearing' as the anchors. One study [40] regarded hearing impairment as having an effect beyond health or HRQoL, so alongside EQ-VAS, another VAS using the best/ worst quality of life as anchors were also reported. The remaining four papers reported a general health VAS and among them, one used 'death' and 'the imaginable best health' as anchors, one used 'imaginable worst/best health' as anchors and for the other two, anchors were not clearly reported.

Time trade-off (TTO) values were obtained without the use of generic measures in 2 studies [33, 37]. The study by Cheng et al. used parents as proxies to assess their deaf children's utility and the TTO compared two alternatives: one being in the current health state without hearing aid for remaining life expectancy and another alternative being in perfect health for a shorter time period. The values in the study by Lee et al. were not actual TTO values but predictions from VAS transformed using a power formula.

A total of 9 studies employed self-reported hearingspecific health-related quality of life measures. This included 3 studies using the Hearing Handicap Inventory 


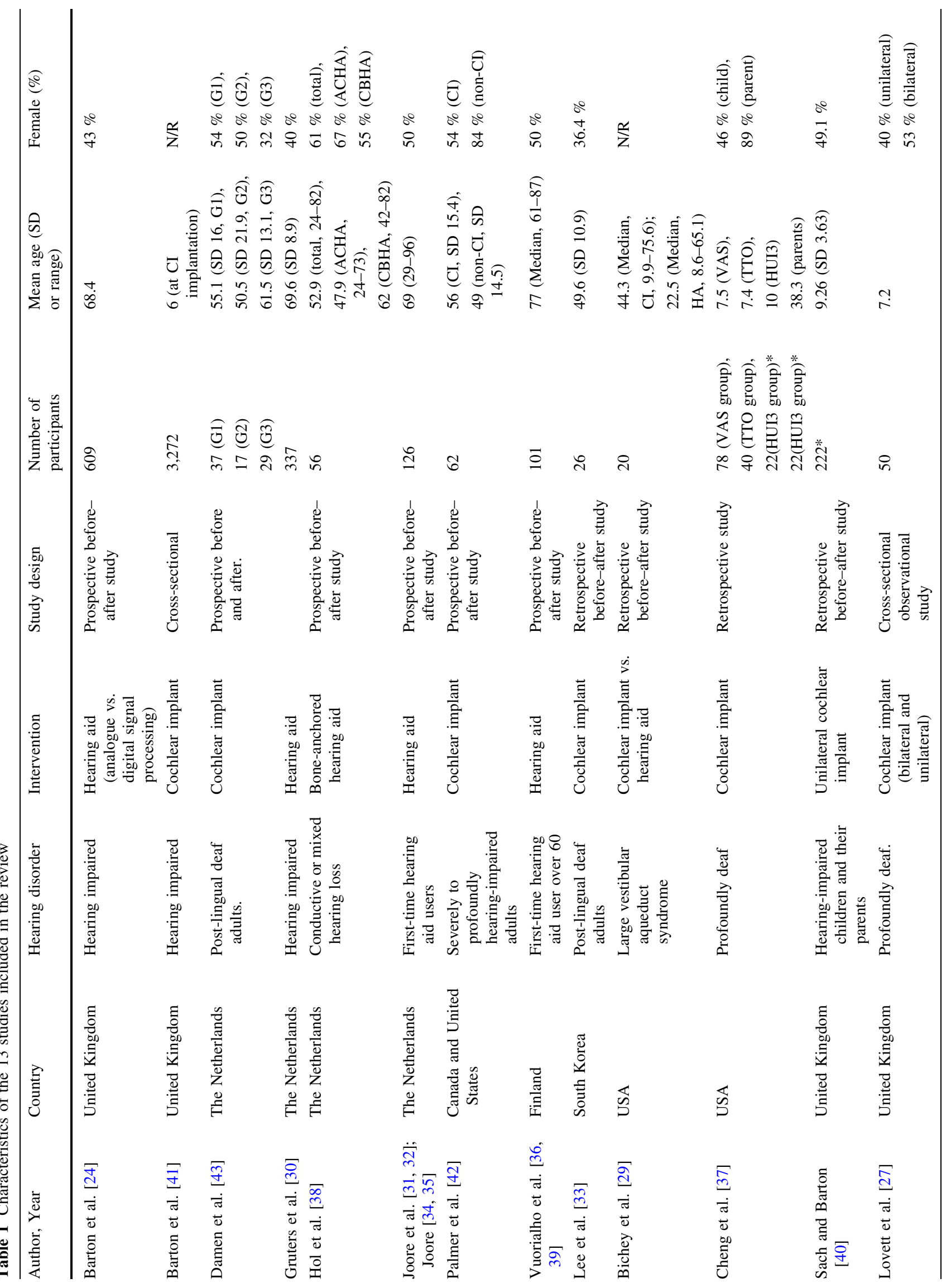


for the Elderly, 2 using the Hearing Handicap and Disability Index, and 1 using the Nijmegen cochlear implant questionnaire, the Speech Spatial and Qualities of hearing scale for parents, Amsterdam Inventory and Audiological Disability Preference Index which is a hearing-specific preference-based measure derived from Amsterdam Inventory. Six studies reported clinical indicators to indicate severity of hearing impairment, including pure-tone average for the best or worst ear without hearing aid and speech identification tests.

Reliability of GPBMs in hearing impairment

The review found little evidence on the reliability assessments of EQ-5D, HUI3 and SF-6D in hearing impairment. No papers reported conducting test-retest experiments. Although not specifically for test-retest reliability purposes, one study [34] reported EQ-5D responses and VAS indices at baseline and asked respondents to recall them 3 months after hearing aid fitting. They did not find any significant difference between the baseline assessment and the recalled assessment of baseline health for EQ-5D.

Construct validity of GPBMs in hearing impairment

Out of the 18 papers include in the review, 7 papers provided information to enable an assessment of the EQ-5D, HUI3 or SF-6D, although most studies were not designed to examine the validity of these measures. The results are summarised in Table 3.

\section{'Known group' differences}

Seven studies presented data to allow an assessment of 'known group' differences where the groups were defined by severity of hearing loss. Using ANOVA, the study by Grutters et al. [30] demonstrated that EQ-5D failed to detect significant differences by hearing loss severity groups, whereas HUI3 detected did. Another study found that EQ-5D differentiated the group with the most severe hearing loss but not groups defined by milder levels of deafness [40]. Barton et al. [41] reported that HUI3 mean scores were different between moderate, severe, profound1, profound 2 and implanted groups defined by the average of pure-tone air-conduction thresholds at the frequencies $0.5,1,2$ and $4 \mathrm{kHz}$ in the better hearing ear, although no statistical test was reported. Palmer et al. [42] showed that HUI3 successfully discriminated between people with hearing aids (0.76) and without hearing aids $(0.58)$ at 6 months $(p<0.001)$ and 12 months after intervention $(p<0.1)$ using $t$ test. Similarly, HUI3 discriminated 2 groups of patients with cochlear implant and with normal hearing aids where the hearing loss severity of 
Table 2 Measures reported in the papers

\begin{tabular}{|c|c|c|c|c|c|c|c|}
\hline \multirow[t]{2}{*}{ Author, Year } & \multicolumn{3}{|c|}{ Generic utility measures } & \multirow{2}{*}{$\begin{array}{l}\text { Direct } \\
\text { valuations } \\
\text { TTO }\end{array}$} & \multirow{2}{*}{$\begin{array}{l}\text { Rating scales } \\
\text { VAS }\end{array}$} & \multirow{2}{*}{$\begin{array}{l}\text { Hearing-specific } \\
\text { measures } \\
-\end{array}$} & \multirow{2}{*}{$\begin{array}{l}\text { Clinical } \\
\text { indicators } \\
-\end{array}$} \\
\hline & EQ-5D & HUI3 & SF-6D & & & & \\
\hline Barton et al. [24] & $\sqrt{ }$ & $\sqrt{ }$ & $\sqrt{ }$ & - & - & - & - \\
\hline Barton et al. [41] & & $\sqrt{ }$ & & & & & AHL \\
\hline Gruters et al. [30] & $\sqrt{ }$ & $\sqrt{ }$ & - & - & - & - & BEPTA \\
\hline Lee et al. [33] & $\sqrt{ }$ & $\sqrt{ }$ & - & $\sqrt{ }$ & $\sqrt{ }$ & - & - \\
\hline Bichey et al. [29] & - & $\sqrt{ }$ & - & - & - & - & PTA \\
\hline Cheng et al. [37]* & - & $\sqrt{ }$ & & $\sqrt{ }$ & $\sqrt{ }$ & - & - \\
\hline Damen et al. [43] & - & $\sqrt{ }$ & - & - & - & NCIQ & $\begin{array}{l}\text { NVA and AN } \\
\text { test }\end{array}$ \\
\hline Lovett et al. [27] & - & $\sqrt{ }$ & - & - & $\sqrt{ }$ & SSQ & - \\
\hline Palmer et al. [42] & - & $\sqrt{ }$ & - & - & - & - & $\begin{array}{l}\text { NU-6; } \\
\text { Audiologic } \\
\text { mean score } \\
\text { for CID } \\
\text { sentence } \\
\text { recognition. }\end{array}$ \\
\hline $\begin{array}{l}\text { Smith-Olinde et al. } \\
\text { [28] }\end{array}$ & - & $\sqrt{ }$ & - & - & - & - & BEPTA \\
\hline Hol et al. [38] & $\sqrt{ }$ & - & - & - & EQ-VAS & HHDI & - \\
\hline Joore et al. [31] & $\begin{array}{l}\text { Index and } \\
\text { responses }\end{array}$ & - & - & - & VAS and EQ-VAS & ADPI & - \\
\hline Joore et al. [32] & $\begin{array}{l}\text { Index and } \\
\text { responses }\end{array}$ & - & - & - & VAS and EQ-VAS & - & - \\
\hline $\begin{array}{l}\text { Vuorialho et al. } \\
\text { [36] }\end{array}$ & $\begin{array}{l}\text { Index and } \\
\text { responses }\end{array}$ & - & - & - & $\sqrt{ }$ & HHIE-S & $\begin{array}{l}\text { BEHL, SRT, } \\
\text { WRS }\end{array}$ \\
\hline Joore et al. [34] & $\sqrt{ }$ & - & - & - & $\sqrt{ }$ and EQ-VAS & - & - \\
\hline Joore et al. [35] & $\sqrt{ }$ & - & - & - & $\sqrt{ }$ and EQ-VAS & $\begin{array}{l}\text { HHIE-S and hearing } \\
\text { aid satisfaction/use }\end{array}$ & - \\
\hline $\begin{array}{l}\text { Sach and Barton } \\
\text { [40] }\end{array}$ & $\sqrt{ }$ & - & - & - & $\begin{array}{l}\text { EQ-VAS and quality of } \\
\text { life VAS }\end{array}$ & - & - \\
\hline $\begin{array}{l}\text { Vuorialho et al. } \\
\text { [39] }\end{array}$ & $\sqrt{ }$ & - & - & - & EQ-VAS & $\begin{array}{l}\text { HHIE-S, hearing aid } \\
\text { satisfaction }\end{array}$ & - \\
\hline
\end{tabular}

EQ-5D EuroQol 5 dimensions, HUI3 Health Utility Index 3, SF- $6 D$ Short-form 6 dimensions, TTO Time trade-off, VAS Visual Analogue Scale, $A H L$ average of pure-tone air-conduction thresholds at the frequencies $0.5,1,2$ and $4 \mathrm{kHz}$ in the better hearing ear, BEPTA (better ear pure-tone average hearing loss for the frequencies $1,000,2,000$ and 4,000 Hz, PTA ear-specific and bilateral four-frequency pure-tone averages, $N C I Q$ the Nijmegen cochlear implant questionnaire, $N V A$ test (an open speech recognition test), $A N$ test (assess suprasegmental identification, a closed-set spondee identification test and a closed-set number of syllables test), SSQ speech, spatial and qualities of hearing scale for parents, $N U-6$ Northwestern University 6 word test, $C I D$ central institute for the deaf, EQ-VAS euroqol Visual Analogue Scale, HHDI Hearing Handicap and Disability Index, $A D P I$ Audiological Disabilities Preference Index, $H H I S-S$ Hearing Handicap Inventory for the elderly, $B E H L$ better ear hearing levels over the frequencies $0.5-4 \mathrm{kHz}, S R T$ speech reception thresholds, WRS word reception scores (\%), $A P H A B$ abbreviated profile of hearing aid benefit

* Parents were proxies

these 2 groups was different according to their pure-tone average. In a study comparing HUI3 and QWB in hearing loss, both scores declined with the degree of hearing loss for children who did not have a cochlear implant with a much greater extent for HUI3 than QWB [28]. A further study of the HUI3 found that it did not differentiate between groups defined according to unilateral or bilateral implantation [27]. However, this finding was also reflected in the VAS measure and may reflect that the additional impact of bilateral implantation in this group is small.

\section{Convergence}

Three studies presented data for an assessment of convergence of EQ-5D and HUI3. HUI3 showed poor correlation with two speech perception tests; however, a hearing-specific quality of life measure also showed similar results [43]. Gruters et al. [30] reported a moderate correlation between EQ-5D and HUI3. Barton et al. [41] reported a regression analysis and showed that CI (grouped by age at implantation and duration of use), the average of pure-tone air-conduction 
Table 3 Summary of validity of EQ-5D, HUI3 in hearing impairments

\begin{tabular}{|c|c|c|c|c|}
\hline Study & Instrument & Assessment & Methods & Summary of results \\
\hline $\begin{array}{l}\text { Barton et al. } \\
\text { [24] }\end{array}$ & $\begin{array}{l}\text { HUI3/EQ-5D/ } \\
\text { SF-6D }\end{array}$ & Convergence & $\begin{array}{l}\text { Correlations between } \\
\text { measures }\end{array}$ & $\begin{array}{l}\text { Moderate to strong correlations were found } \\
\text { between HUI3, EQ-5D and SF-6D. }\end{array}$ \\
\hline $\begin{array}{l}\text { Barton et al. } \\
\text { [41] }\end{array}$ & HUI3 & $\begin{array}{l}\text { Known } \\
\text { groups(severity) } \\
\text { Convergence }\end{array}$ & $\begin{array}{l}\text { HUI } 3 \text { scores and severity } \\
\text { groups defined by AHL } \\
\text { level }\end{array}$ & $\begin{array}{l}\text { HUI3 mean scores were different between } \\
\text { moderate, severe, profound1, profound } 2 \\
\text { and implanted groups (significance not } \\
\text { reported) } \\
\text { CI (grouped by age at implantation and } \\
\text { duration of use), AHL, gender were } \\
\text { significant predictor of HUI3 }(p<0.01)\end{array}$ \\
\hline $\begin{array}{l}\text { Bichey et al. } \\
\text { [29] }\end{array}$ & HUI3 & $\begin{array}{l}\text { Known groups } \\
\text { (severity) }\end{array}$ & $\begin{array}{l}\text { HUI3 scores and PTA } \\
\text { (presented by CI and HA } \\
\text { group }\end{array}$ & $\begin{array}{l}\text { HUI3 mean scores: } \\
0.82 \text { (CI) versus. } 0.62 \text { (HA) } \\
\text { Consistent with PTA. } \\
\text { No statistical test reported. }\end{array}$ \\
\hline $\begin{array}{l}\text { Damen et al. } \\
\text { [43] }\end{array}$ & HUI3 & Convergence & $\begin{array}{l}\text { Spearman rho correlations } \\
\text { between mean score of } \\
\text { different measures at the } \\
\text { follow-up }\end{array}$ & $\begin{array}{l}\text { Correlation coefficients: } \\
0.33 \text { (HUI3 and AN test, } p<0.05 \text { ) } \\
0.39 \text { (HUI3 and NVA test, } p<0.05 \text { ) } \\
0.48 \text { (NCIQ and AN test, } p<0.05 \text { ) } \\
0.32 \text { (NCIQ and NVA test, } p<0.05 \text { ) }\end{array}$ \\
\hline $\begin{array}{l}\text { Lovett et al. } \\
\text { [27] }\end{array}$ & HUI3 & $\begin{array}{l}\text { Known groups } \\
\text { (severity) }\end{array}$ & $\begin{array}{l}\text { HUI3 index scores and } \\
\text { SSQ, VAS scores } \\
\text { presented by unilateral } \\
\text { and bilateral implantation } \\
\text { groups }\end{array}$ & $\begin{array}{l}\text { A significant difference }(p<0.05) \text { in favour } \\
\text { of bilateral (SSQ); } \\
\text { No significant }(p=0.2) \text { differences detected } \\
\text { (HUI3 and VAS) }\end{array}$ \\
\hline $\begin{array}{l}\text { Palmer et al. } \\
\text { [42] }\end{array}$ & HUI3 & $\begin{array}{l}\text { Known groups } \\
\text { (severity) }\end{array}$ & $\begin{array}{l}\text { HUI3 index scores } \\
\text { presented by CI and non- } \\
\text { CI implant groups at } \\
\text { enrolment, } 6 \text { months and } \\
12 \text { months after CI } \\
\text { implant. }\end{array}$ & $\begin{array}{l}\text { Difference between } \mathrm{CI} \text { and non-CI groups by } \\
\text { HUI3: } \\
\text { Not significant (baseline) and significant } \\
(p<0.1) \text { difference }(0.76 \text { for CI and } 0.58 \\
\text { for non-CI) at both } 6 \text { and } 12 \text { months after } \\
\text { intervention. }\end{array}$ \\
\hline $\begin{array}{l}\text { Smith-Olinde } \\
\text { et al. [28] }\end{array}$ & HUI3 & $\begin{array}{l}\text { Known groups } \\
\text { (severity) }\end{array}$ & $\begin{array}{l}\text { HUI3 utility index } \\
\text { presented by } 4 \text { groups } \\
\text { defined by the degree of } \\
\text { hearing loss }\end{array}$ & $\begin{array}{l}\text { Both HUI3 and QWB scores declined with } \\
\text { the degree of hearing loss where a greater } \\
\text { extent for HUI3 than QWB. No statistical } \\
\text { significance was presented }\end{array}$ \\
\hline $\begin{array}{l}\text { Gruters et al. } \\
\text { [30] }\end{array}$ & $\begin{array}{l}\text { EQ-5D (UK and } \\
\text { Dutch tariff), } \\
\text { HUI3 }\end{array}$ & $\begin{array}{l}\text { Known groups (age } \\
\text { gender and } \\
\text { severity) } \\
\text { Convergence }\end{array}$ & $\begin{array}{l}\text { Utility scores compared } \\
\text { between age, gender (EQ- } \\
\text { 5D) and clinically } \\
\text { distinctive groups (HUI3) } \\
\text { Agreements between utility } \\
\text { scores by Kendall's Tau } \\
\text { correlation and ICC }\end{array}$ & $\begin{array}{l}\text { Significant differences detected: } \\
\text { Age and gender (by EQ-5D); } \\
\text { Clinical groups (by HUI3). } \\
\text { Kendall's Tau correlations: } \\
0.36-0.41 \text { (between EQ-5D with UK or } \\
\text { Dutch tariff and HUI2, HUI3) } \\
\text { ICC: } 0.44-0.51 \text { (between utility measures) }\end{array}$ \\
\hline $\begin{array}{l}\text { Sach and } \\
\text { Barton [40] }\end{array}$ & EQ-5D & $\begin{array}{l}\text { Known groups } \\
\text { (through } \\
\text { regressions) }\end{array}$ & $\begin{array}{l}\text { Multiple linear regression } \\
\text { was estimated between } \\
\text { the child's EQ-5D scores } \\
\text { and CAP, as well as other } \\
\text { variables) }\end{array}$ & $\begin{array}{l}\text { Statistically significant coefficients } \\
(p<0.05) \text { for children with/without } \\
\text { additional disabilities, gender, more severe } \\
\text { deaf condition (measured by CAP); } \\
\text { Non-statistical significant coefficients } \\
(p>0.05) \text { for children having mild deaf (in } \\
\text { the top three levels of the CAP) and other } \\
\text { socio-economic factors. }\end{array}$ \\
\hline
\end{tabular}

HUI3 Health Utility Index 3, AHL average of pure-tone air-conduction thresholds at the frequencies $0.5,1,2$ and $4 \mathrm{kHz}$ in the better hearing ear, $P T A$ pure-tone average, $C I$ cochlear implant, $H A$ hearing aid, NCIQ the Nijmegen cochlear implant questionnaire, SSQ speech, spatial and qualities of hearing scale for parents, $V A S$ Visual Analogue Scale, $Q W B$ Quality of well-being scale, $E Q-5 D$ euroqol 5 dimensions, $I C C$ intraclass correlation, $C A P$ categories of auditory perception 
Table 4 Summary of responsiveness for EQ-5D, HUI3 and SF-6D in hearing impairments

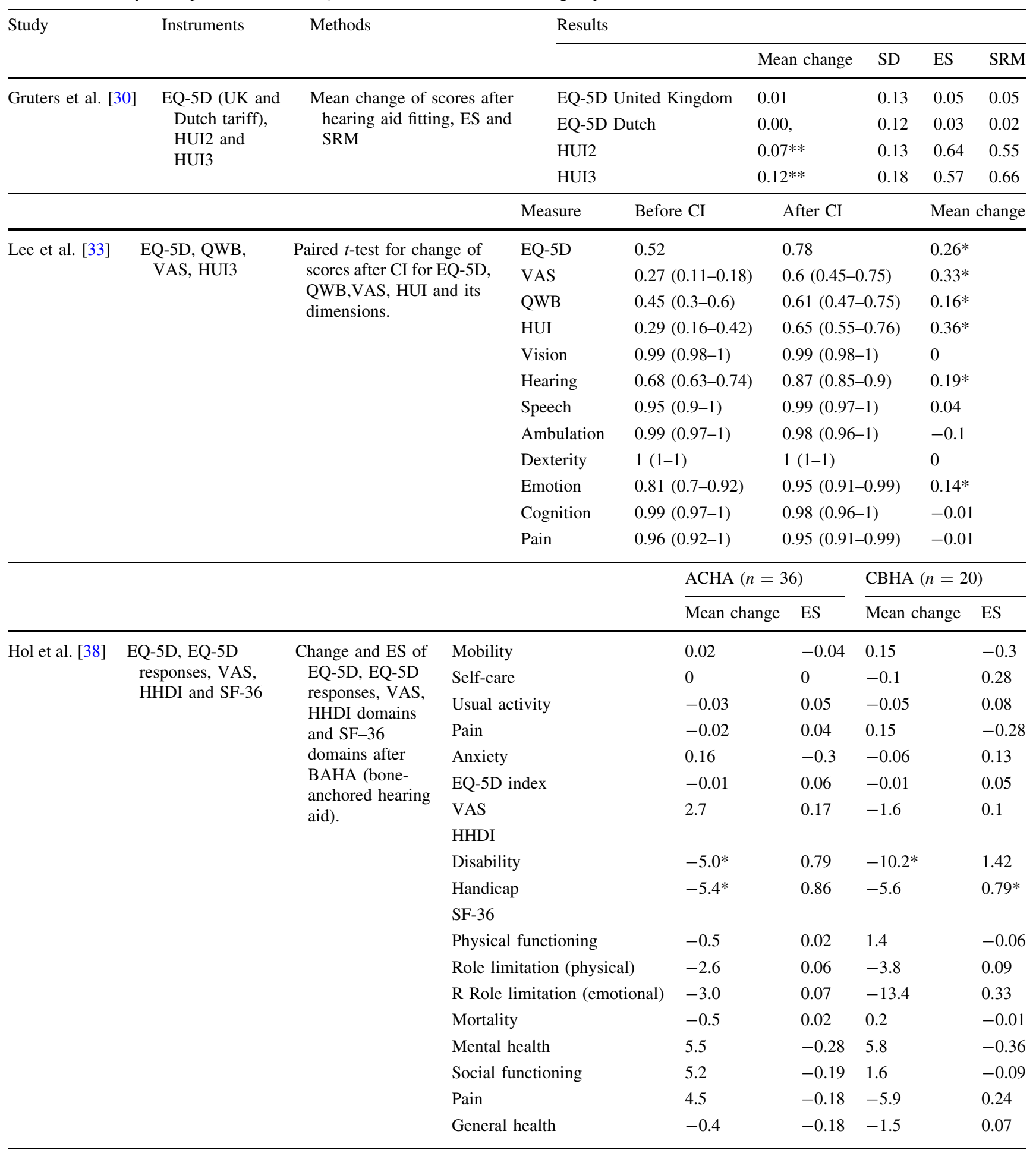


Table 4 continued

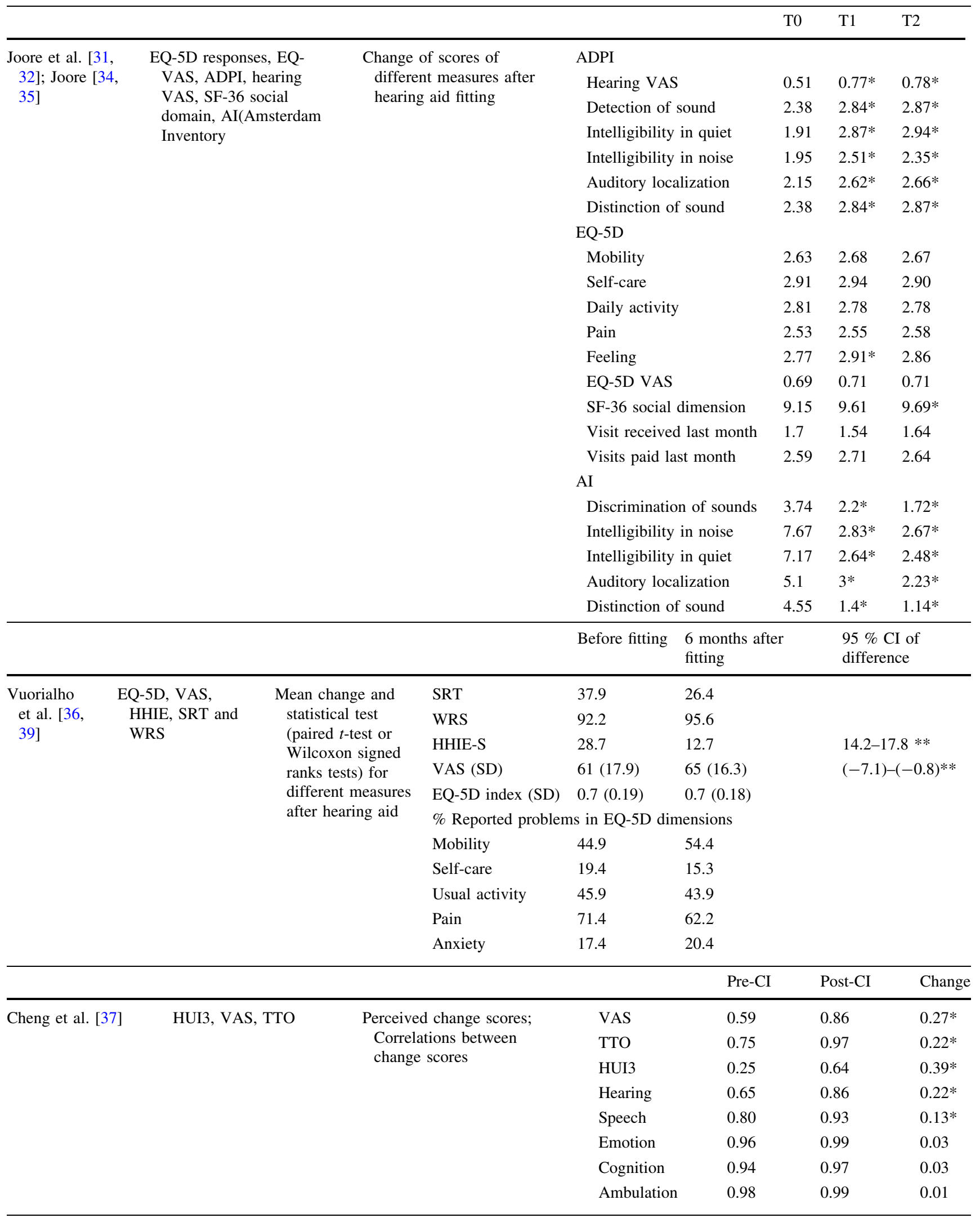


Table 4 continued

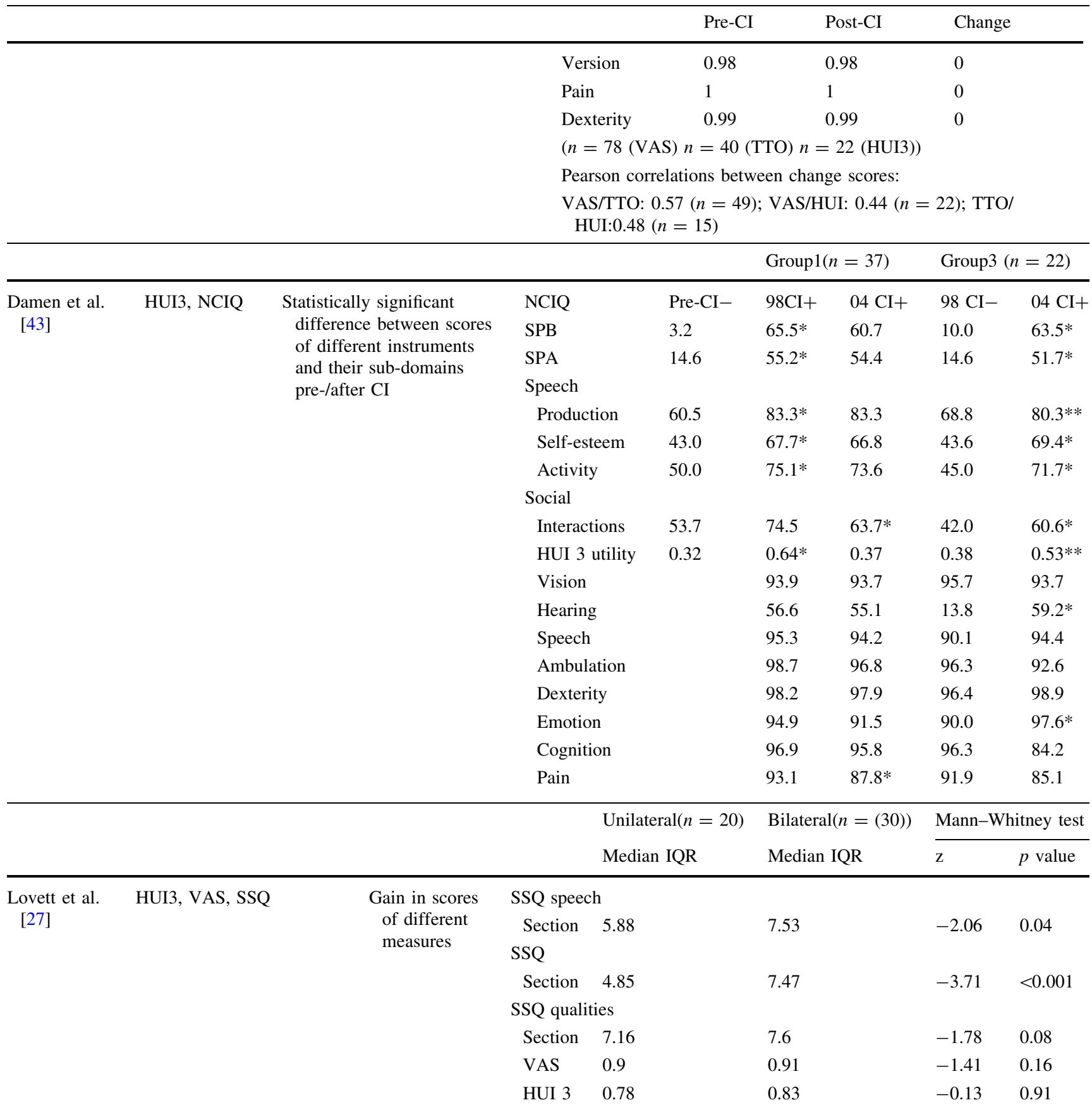

$\overline{E Q-5 D}$ euro qol 5 dimension, $H U I 2$ Health Utility Index 2, HUI3 Health Utility Index 3, ES effect size, SRM standard response mean, $C I$ cochlear implant, VAS Visual Analogue Scale, HHDI Hearing Handicap and Disability Index, SF-36 Short-form 36, BAHA bone-anchored hearing aid, $A C H A$ used air-conduction hearing aid, $C B H A$ conventional bone-conduction hearing aid, NCIQ the Nijmegen cochlear implant questionnaire, ADPI Audiological Disabilities Preference Index, HHIS-S hearing handicap inventory for the elderly, SSQ speech, spatial and qualities of hearing scale for parents, $N V A$ test an open speech recognition test, $A N$ test assess suprasegmental identification, a closed-set spondee identification test and a closed-set number of syllables test, DEPTA better ear pure-tone average hearing loss for the frequencies 1,000, 2,000 and $4,000 \mathrm{~Hz}, \mathrm{NU}-6$, Northwestern University 6 word test, $B E H L$ better ear hearing levels over the frequencies $0.5-4 \mathrm{kHz}, S R T$ speech reception thresholds, WRS word reception scores (\%), PTA ear-specific and bilateral four-frequency pure-tone averages, APHAB abbreviated profile of hearing aid benefit

$* p<0.05, * * p<0.01$ 
Table 5 Overall performances of EQ-5D, HUI3 and SF-6D in hearing impairment

\begin{tabular}{|c|c|c|c|c|c|c|c|c|c|}
\hline & \multicolumn{2}{|c|}{ Known group (Severity) } & \multicolumn{2}{|c|}{$\begin{array}{l}\text { Known group } \\
\text { (case-control) }\end{array}$} & \multicolumn{2}{|c|}{$\begin{array}{l}\text { Known group } \\
\text { (other) }\end{array}$} & \multirow[t]{2}{*}{ Correlation } & \multicolumn{2}{|c|}{$\begin{array}{l}\text { Responsive } \\
\text { (change) }\end{array}$} \\
\hline & Cons & Sig & Cons & Sig & Cons & Sig & & Cons & Sig \\
\hline \multicolumn{10}{|l|}{$E Q-5 D$} \\
\hline Grutters et al. [30] & & & & & $\sqrt{ }$ & $\sqrt{ }$ & Moderate & $x$ & $x$ \\
\hline Sach and Barton [40] & Severe $\sqrt{ }$ Mild $\times$ & $\sqrt{ } \times$ & & & $\sqrt{ }$ & $\sqrt{ }$ & & & \\
\hline Lee et al. [33] & & & & & & & & $\sqrt{ }$ & $\sqrt{ }$ \\
\hline Hol et al. [38] & & & & & & & & $\times$ & $x$ \\
\hline $\begin{array}{c}\text { Joore et al. }[31,32] \text {; } \\
\text { Joore }[34,35]\end{array}$ & & & & & & & & $?$ & $x$ \\
\hline Vuorialho et al. $[36,39]$ & & & & & & & & $x$ & $x$ \\
\hline \multicolumn{10}{|l|}{ HUI 3} \\
\hline Barton et al. [24] & $\sqrt{ }$ & $\mathrm{N} / \mathrm{R}$ & & & & & & & \\
\hline Bichey et al. [29] & $\sqrt{ }$ & $\mathrm{N} / \mathrm{R}$ & & & & & & & \\
\hline Grutters et al. [30] & $\sqrt{ }$ & $\sqrt{ }$ & & & & & Moderate & $\sqrt{ }$ & $\sqrt{ }$ \\
\hline Palmer et al. [42] & $\sqrt{ }$ & $\sqrt{ }$ & & & & & & & \\
\hline Smith-Olinde et al. [28] & $\sqrt{ }$ & $\mathrm{N} / \mathrm{R}$ & & & & & & & \\
\hline Lee et al. [33] & & & & & & & & $\sqrt{ }$ & $\sqrt{ }$ \\
\hline Cheng et al. [37] & & & & & & & & $\sqrt{ }$ & $\sqrt{ }$ \\
\hline Damen et al. [43] & & & & & & & Moderate (sig) & $\sqrt{ }$ & $\sqrt{ }$ \\
\hline Lovett et al. [27] & $\sqrt{ }$ & $\times$ & & & & & & $\sqrt{ }$ & $x$ \\
\hline \multicolumn{10}{|l|}{$S F-6 D$} \\
\hline Barton et al. [24] & & & & & & & Moderate to strong & & \\
\hline
\end{tabular}

Cons consistent with other measures, sig statistically significant

$\sqrt{ }$ : Yes ?: Mixed evidence $\times$ : No N/R: no report

thresholds at the frequencies $0.5,1,2$ and $4 \mathrm{kHz}$ in the better hearing ear, and gender were significant predictor of HUI3 $(p<0.01)$ in a large cross-sectional study. HUI3 scores apart from this, no other papers reported correlations between health-related quality of life measures with clinical indicators of hearing loss. Barton et al. [24] reported strong correlations between EQ-5D, HUI3 and SF-SD in their study.

\section{Responsiveness of GPBMs in hearing impairment}

Twelve papers involved a total of 8 studies that provided adequate information to allow an assessment of responsiveness of EQ-5D and/or HUI3 (see Table 4). Only two studies were specifically designed to examine responsiveness of different measures and responsiveness indices such as effect size and standard response mean were reported $[38,39]$.

\section{Comparison between GPBMs}

Comparison of mean change scores of different GPBMs using statistical tests were reported by Gruter et al. [30] and Lee et al. [33] (See below Table 4 for details). Gruter et al.'s study found that HUI2 and HUI3 detected statistically significant change after cochlear implant fitting $(0.07$ and 0.12 , respectively), whereas change scores of EQ-5D were smaller and not statistically significant (0.01). In terms of effect size, HUI2 and HUI3 were high (0.57 and 0.64 , respectively), whereas the change in EQ-5D was very small (0.02 and 0.05 for both UK and Dutch tariffs). The study by Lee et al. demonstrated that the increase in scores of the GPBMs, including EQ-5D (0.26), VAS (0.33), HUI3 (0.36) and QWB (0.16), was all statistically significant following cochlear implantation. For HUI3 dimensions, score increases for hearing (0.19) and emotion (0.14) was statistically significant $(p<0.05)$, whereas non-significant for other dimensions. The results suggest that the EQ-5D was responsive in capturing larger improvements in hearing as in the study by Lee et al. but was not able to capture the smaller levels of improvement shown in the study by Grunter et al.

\section{Responsiveness of EQ-5D}

Eight papers reported the responsiveness of EQ-5D without the other 2 generic measures by comparing them with 
EQ-VAS, hearing VAS or other hearing-specific measures, which involved a total of 4 separate studies. In these studies, no statistically significant changes before and after the hearing intervention were detected by the EQ-5D [31, 32, 34, $35,38,39]$ and the effect size where reported was very low [38]. Whereas statistically significant improvements were shown in VAS scores [32, 34-36, 39], and condition-specific measures such as two sub-domains (disability and handicap) of Hearing Handicap and Disability Index [38], overall scores of the Hearing Handicap Inventory for the Elderly and its 2 sub-domain scores [36, 39], and the 5 questions of Amsterdam Inventory and Audiological Disabilities Preference Index [35]. Joore's study reported the self-perceived SF-36 social functioning which was significantly improved after hearing aid fitting in long term.

\section{Responsiveness of HUI3}

Three papers reported responsiveness of HUI3 without the other 2 generic measures, comparing with VAS/TTO and hearing-specific measures [27, 37, 43]. Cheng et al. found that the change of HUI3 overall score (0.39) was higher than both VAS score (0.27) and TTO (0.22) after cochlear implant fitting, but all were statistically significant $(p<0.1)$. Only the change scores of hearing and speech dimension of HUI3 were significant and the hearing dimension had the biggest change score while scores of other dimensions were stable over time. Moderate correlations (around 0.48 ) between change scores of VAS, TTO and HUI3 were found [43].

\section{Discussion and conclusions}

The 18 papers (14 studies) included in this review provide useful information to assess the validity and responsiveness of GPBMs for use in hearing impairment. A summary of the overall performance of the $3 \mathrm{GPBMs}$ is provided in Table 5. There was heterogeneity in the studies reviewed, in terms of study design, patient populations, which needs to be taken into account when interpreting the findings.

Overall, the HUI3 was the most commonly used measure in the studies. In all 6 cases, the HUI3 detected difference between groups defined by their severity of hearing impairment and 4 out of 5 cases detected statistically significant changes as a result of intervention. Differences picked up by the HUI3 were driven by the hearing dimensions, and also, in some cases, the speech dimension and the emotion dimension. On the other hand, the findings of the review suggested relatively poor responsiveness of EQ-5D in this condition as in 4 out of 5 cases EQ-5D failed to detected change. The only study that allowed an assessment of known groups using the EQ-5D suggested it only had weak ability to discriminate difference between severity groups. Only one study involved the SF-6D, thus the information is too limited to conclude on its performance. Converting published mean SF-36 scores into SF$6 \mathrm{D}$ would not help since psychometric testing requires individual level data.

Two studies reported validity of EQ-5D where the results were mixed when the groups were defined by severity of hearing impairment [40]. In terms of responsiveness, EQ$5 \mathrm{D}$ did not demonstrate statistically significant changes after hearing aid fitting but there were statistically significant changes detected by clinical indicators or conditionspecific measures. The EQ-5D appears to reflect less, or often no, change/difference compared to the HUI3 and clinical measures. Possible reasons for this include the EQ$5 \mathrm{D}$ not capturing important effects of hearing on quality of life, or that the changes/differences in hearing have little impact on overall quality of life (e.g. because the level of change is small or people have adapted to their hearing loss and value other aspects of health more). Also, the use of clinical measures or else for grouping hearing impairment severity may be regarded as poor indicators to use for testing construct validity. However, given that significant differences were found for HUI3 and hearing-specific health-related quality of life measures, it suggests that the lack of significant differences for EQ-5D is a concern.

There were 2 exceptions to the poor performance of EQ5D: one study demonstrated a statistically significant improvement in EQ-5D index scores after cochlear implantation and in another study, the EQ-5D differentiated between severe hearing loss but not in different levels of milder hearing loss. Although EQ-5D utility indices remained stable over time, 1 study showed that the proportion of respondents who reported problems for dimensions of EQ-5D increased or decreased. Another study treated responses of EQ-5D dimension as continuous variables to compare mean responses before and after intervention, which was judged to be problematic for analysis. There were 2 studies where the HUI3 reflected differences, but much smaller differences were found in the EQ-5D utilities.

It is perhaps unsurprising that HUI3 performs well as it explicitly includes a hearing dimension. The lack of a direct reference to an impairment or symptom in EQ-5D does not mean that, by definition, its effects will not be captured; however, this review suggests that EQ-5D may perform poorly in this particular type of condition. A fivelevel version of the EQ-5D has recently been developed and this may overcome the problem if it is simply one of the sensitivity. However, it may be related to a lack of relevant dimensions to pick up the impact of hearing loss. Evidence is required using the 5-level version to confirm 
this hypothesis. Another approach to the problem might be to use a condition-specific preference-based measure for hearing like the one developed by Yang et al. for asthma [44] or Rowen et al. in cancer [45]. The problem with using condition-specific measures is that they may miss important side effects of treatment and the values may exaggerate the impact of the conditions due to focusing effects by member of the general public [46]. This is the reason for ongoing research into developing bolt-ons to the EQ-5D to cover those dimensions that appear to be missing for cognition in EQ-5D [47], and in the same way, one could be developed for hearing. In the meantime, the best option appears to be to use HUI3.

It cannot always be assumed that a generic measure should reflect the change of health states which a condition-specific measure detects. Disease- or condition-specific measures are tailored to the condition of interest and are therefore more focussed on the condition of interest and may be more sensitive to change. However, they may not capture the broader impacts of the condition on healthrelated quality of life. In addition, the general population (or indeed the patients) may not regard the change as sufficiently important when valuing health. Interestingly, in this study, not only GPBMs, but also the hearing-specific measures showed poor correlations with clinical indicators. This emphasises the importance of including patientreported outcome measures in the evaluations of health care interventions. In addition, preference-based measures can reflect how changes in health states are valued, in relation to other aspects of health.

This is the first-time information on the validity and responsiveness of GPBMs that have been comprehensively reported and analysed in hearing impairment. This paper reports important findings for the use of GPBMs of health to compare the impact of hearing loss on healthrelated utility. The results indicate that HUI3 is an appropriate measure for use in hearing impairment given its good performance of validity and responsiveness. EQ$5 \mathrm{D}$ was not responsive to modest changes in hearing impairment, and the limited evidence suggested it has weak validity in this condition. Very little evidence was found for SF-6D.

Acknowledgments This review has been conducted as part of the NICEQoL project, which is funded by the Medical Research Council as part of the MRC-NIHR Methodology Research Programme (ref: G0901486). The authors would like to thank Pippa Evans for undertaking the literature search. The authors would also like to thank Aki Tsuchiya and Donna Rowen from the NICEQoL project team for their comments on preliminary findings of this review.

Open Access This article is distributed under the terms of the Creative Commons Attribution License which permits any use, distribution, and reproduction in any medium, provided the original author(s) and the source are credited.

\section{Appendix 1: Search strategy used for the hearing review in Medline}

1. (euroqol or euro qol or eq5d or eq $5 \mathrm{~d}$ or eq-5d or (euro adj qol) Or eur adj qual) or (eq adj 5d)).mp

2. (hui 3 or hui 3 or health utilities index mark 3 or health utilities mark three or hui III or huiIII).mp

3. (sf6D or sf $6 \mathrm{D}$ or short form $6 \mathrm{D}$ or shortform $6 \mathrm{D}$ or sf six D or sfsixD or shortform six D or short form sixD or sf-6d or 6d or 6-d or 6 dimension).mp

4. (hearing disorder or dysacusis or paracousis or paracusis or Distorted hearing).mp

5. (hearing loss or hearing complaints or hearing aids or cochlear implants).mp. $[\mathrm{mp}=$ title, original title, abstract, name of substance word, subject heading word, unique identifier]

6. hearing disorders/

7. 1 or 2 or 3

8. 4 or 5 or 6

9. 7 and 8

\section{References}

1. National Institute of Health and Clinical Excellence (NICE) (2008). NICE Guide to the Methods of Technology Appraisal. NICE, London .

2. Canadian Coordinating Office for Health Technology Assessment (CCOHTA) (2003). Canada. Canada Common Drug Review Submission Guidelines for Manufacturers.

3. Scotish Medicine Consortium (SMC) (2007). Scotlant. Guidance to Manufacturers for Completion of New Product Assessment Form (NPAF). .

4. Torrance, G. W. (1986). Measurement of health state utilities for economic appraisal. Journal of Health Economics, 5(1), 1.

5. Brooks, R. (1996). EuroQol: The current state of play. Health Policy, 37(1), 53-72.

6. Dolan, P. (1997). Modeling valuations for EuroQol health states. Medical Care, 35(11), 1095-1108.

7. Brazier, J., Roberts, J., \& Deverill, M. (2002). The estimation of a preference-based measure of health from the SF-36. Journal of Health Economics, 21(2), 271-292.

8. Feeny, D., Furlong, W., Torrance, G. W., Goldsmith, C. H., Zhu, Z., DePauw, S., et al. (2002). Multiattribute and single-attribute utility functions for the health utilities index mark 3 system. Medical Care, 40(2), 113-128.

9. Herdman, M., Gudex, C., Lloyd, A., Janssen, M. F., Kind, P., Parkin, D. et al. (2011). Development and preliminary testing of the new five-level version of EQ-5D (EQ-5D-5L). Quality of Life Research, 20(10), 1727-1736.

10. Hawthorne, G., Richardson, J., \& Day, N. A. (2001). A comparison of the assessment of quality of life (AQoL) with four other generic utility instruments. Annals of Medicine, 33(5), 358-370.

11. Longworth, L., \& Bryan, S. (2003). An empirical comparison of EQ-5D and SF-6D in liver transplant patients. Health Economics, 12(12), 1061-1067.

12. Brazier, J. E., Tsuchiya, A., Roberts, J., \& Busschbach, J. (2004). A comparison of the EQ-5D and the SF-6D across seven patient groups. Health Economics, 13(9), 873-884. 
13. Feeny, D., Wu, L., \& Eng, K. (2004). Comparing short form 6D, standard gamble, and health utilities index mark 2 and mark 3 utility scores: Results from total hip arthroplasty patients. Quality of Life Research, 13(10), 1659-1670.

14. Marra, C. A., Woolcott, J. C., Kopec, J. A., Shojania, K., Offer, R., Brazier, J. E., et al. (2005). A comparison of generic, indirect utility measures (the HUI2, HUI3, SF-6D, and the EQ-5D) and diseasespecific instruments (the RAQoL and the HAQ) in rheumatoid arthritis. Social Science and Medicine, 60(7), 1571-1582.

15. National Institute of Health and clinical Excellence (NICE) (2004). NICE Guide to the Methods of Technology Appraisal. NICE, London.

16. Brazier, J. E., Rowen, D., Mavranezouli, I., Tsuchiya, A., Young, T., Yang, Y., et al. (2012). Developing and testing methods for deriving preference-based measures of health from condition specific measures (and other patient based measures of outcome). Health Technology Assessment, 16(32), 1366-5278.

17. Tosh, J., Brazier, J., Evans, P., \& Longworth, L. (2012). A review of generic preference-based measures of health-related quality of life in visual disorders. Value in Health, 15(1), 118-127.

18. Papaioannou, D., Brazier, J., \& Parry, G. (2011). How valid and responsive are generic health status measures, such as EQ-5D and SF-36, in Schizophrenia? A Systematic Review. Value Health, 14(6), 907-920.

19. Harper, R., Brazier, J. E., Waterhouse, J. C., Walters, S. J., Jones, N. M., \& Howard, P. (1997). Comparison of outcome measures for patients with chronic obstructive pulmonary disease (COPD) in an outpatient setting. British Medical Journal, 52(10), 879.

20. Sand, P. K., Staskin, D., Miller, J., Diokno, A., Sant, G. R., Davila, G. W., et al. (1999). Effect of a urinary control insert on quality of life in incontinent women. International Urogynecology Journal, 10(2), 100-105.

21. Kobelt, G., Kirchberger, I., \& MaloneLee, J. (1999). Ouality of life aspects of the overactive bladder and the effect of treatment with tolterodine. British journal of urology (Print), 83(6), 583-590.

22. Brazier, J., \& Deverill, M. (1999). A checklist for judging preference based measures of health related quality of life: Learning from psychometrics. Health Economics, 8(1), 41-51.

23. Dalton, D. S., Cruickshanks, K. J., Klein, B. E. K., Klein, R., Wiley, T. L., \& Nondahl, D. M. (2003). The impact of hearing loss on quality of life in older adults. The Gerontologist, 43(5), 661.

24. Barton, G. R., Bankart, J., \& Davis, A. C. (2005). A comparison of the quality of life of hearing-impaired people as estimated by three different utility measures. International Journal of Audiology, 44(3), 157-163.

25. Pickard, A. S., Wilke, C. T., Lin, H. W., \& Lloyd, A. (2007). Health utilities using the EQ-5D in studies of cancer. Pharmacoeconomics, 25(5), 365-384.

26. Streiner, D. L., \& Norman, G. R. (2008). Health measurement scales: A practical guide to their development and use. USA: Oxford University Press.

27. Lovett, R. E. S., Kitterick, P. T., Hewitt, C. E., \& Summerfield, A. Q. (2010). Bilateral or unilateral cochlear implantation for deaf children: an observational study. Archives of Disease in Childhood, 95(2), 107-112.

28. Smith-Olinde, L., Grosse, S. D., Olinde, F., Martin, P. F., \& Tilford, J. M. (2008). Health state preference scores for children with permanent childhood hearing loss: A comparative analysis of the QWB and HUI3. Quality of Life Research, 17(6), 943-953.

29. Bichey, B. G., Hoversland, J. M., Wynne, M. K., \& Miyamoto, R. T. (2002). Changes in quality of life and the cost-utility associated with cochlear implantation in patients with large vestibular aqueduct syndrome. Otology and neurotology : official publication of the American Otological Society, American Neurotology Society [and] European Academy of Otology and Neurotology, 7(3), 323.

30. Grutters, J. P. C., Joore, M. A., van der Horst, F., Verschuure, H., Dreschler, W. A., \& Anteunis, L. J. C. (2007). Choosing between measures: Comparison of EQ-5D, HUI2 and HUI3 in persons with hearing complaints. Quality of Life Research, 16(8), 1439-1449.

31. Joore, M., Brunenberg, D., Zank, H., van der Stel, H., Anteunis, L., Boas, G., et al. (2002). Development of a questionnaire to measure hearing-related health state preferences framed in an overall health perspective. International Journal of Technology Assessment in Health Care, 18(03), 528-539.

32. Joore, M. A., van der Stel, H., Peters, H. J. M., Boas, G. M., \& Anteunis, J. C. (2003). The cost-effectiveness of hearing-aid fitting in the Netherlands. Archives of Otolaryngology-Head and Neck Surgery, 129(3), 297-304.

33. Lee, H. Y., Park, E. C., Joong Kim, H., Choi, J. Y., \& Kim, H. N. (2006). Cost-utility analysis of cochlear implants in Korea using different measures of utility. Acta Oto-Laryngologica, 126(8), 817-823.

34. Joore, M. A. (2002). Response shift in the measurement of quality of life in hearing impaired adults after hearing aid fitting. Quality of life research: An international journal of quality of life aspects of treatment, care and rehabilitation, 11(4), 299-307.

35. Joore, M. A. B. (2003). Societal effects of hearing aid fitting among the moderately hearing impaired. International Journal of Audiology, 42(3), 152-160.

36. Vuorialho, A., Karinen, P., \& Sorri, M. (2006). Effect of hearing aids on hearing disability and quality of life in the elderly. International Journal of Audiology, 45(7), 400-405.

37. Cheng, A. K., Rubin, H. R., Powe, N. R., Mellon, N. K., Francis, H. W., \& Niparko, J. K. (2000). Cost-utility analysis of the cochlear implant in children. JAMA: The journal of the American Medical Association, 284(7), 850-856.

38. Hol, M. K. S., Spath, M. A., Krabbe, P. F. M., van der Pouw, C. T. M., Snik, A. F. M., Cremers, C. W. R. J., et al. (2004). The bone-anchored hearing aid: Quality-of-life assessment. Archives of Otolaryngology-Head and Neck Surgery, 130(4), 394-399.

39. Vuorialho, A., Karinen, P., \& Sorri, M. (2006). Counselling of hearing aid users is highly cost-effective. European Archives of Oto-Rhino-Laryngology, 263(11), 988-995.

40. Sach, T. H., \& Barton, G. R. (2007). Interpreting parental proxy reports of (health-related) quality of life for children with unilateral cochlear implants. International Journal of Pediatric Otorhinolaryngology, 71(3), 435-445.

41. Barton, G. R., Stacey, P. C., Fortnum, H. M., \& Summerfield, A. Q. (2006). Hearing-impaired children in the United Kingdom. IV: Cost-effectiveness of pediatric cochlear implantation (Structured abstract). Ear and Hearing, 5, 575-588.

42. Palmer, C. S., Niparko, J. K., Wyatt, J. R., Rothman, M., \& de Lissovoy, G. (1999). A prospective study of the cost-utility of the multichannel cochlear implant. Archives of OtolaryngologyGÇöHead and Neck Surgery, 125(11), 1221.

43. Damen, G. W. J. A., Beynon, A. J., Krabbe, P. F. M., Mulder, J. J. S., \& Mylanus, E. A. M. (2007). Cochlear implantation and quality of life in postlingually deaf adults: Long-term follow-up. Otolaryngology-Head and Neck Surgery, 136(4), 597-604.

44. Yang, Y., Brazier, J. E., Tsuchiya, A., \& Young, T. A. (2011). Estimating a preference-based index for a 5-dimensional health state classification for asthma derived from the asthma quality of life questionnaire. Medical Decision Making, 31(2), 281-291.

45. Rowen, D., Brazier, J. E., Young, T. A., Gaugrist, S., Craig, B. M., King, M. T., \& Velikova, G. (2011). Deriving a preferencebased measure for cancer using the EORTC QLQ-C30. Value in Health, 14(5), 721-731.

46. Brazier, J., \& Tsuchiya, A. (2010). Preference-based conditionspecific measures of health: What happens to cross programme comparability? Health Economics, 19(2), 125-129.

47. Krabbe, P. F. M., Stouthard, M. E. A., Essink-Bot, M. L., \& Bonsel, G. J. (1999). The effect of adding a cognitive dimension to the EuroQol multiattribute health-status classification system. Journal of Clinical Epidemiology, 52(4), 293-301. 